\title{
School-based interpersonal psychotherapy improves depression in older adolescents
}

Mufson L, Dorta KP, Wickramaratne P, et al. A randomized effectiveness trial of interpersonal psychotherapy for depressed adolescents. Arch Gen Psychiatry 2004;61:577-84.

\section{What is the effectiveness of interpersonal psychotherapy compared with school-based psychotherapy in adolescents with depression?}

\section{METHODS}

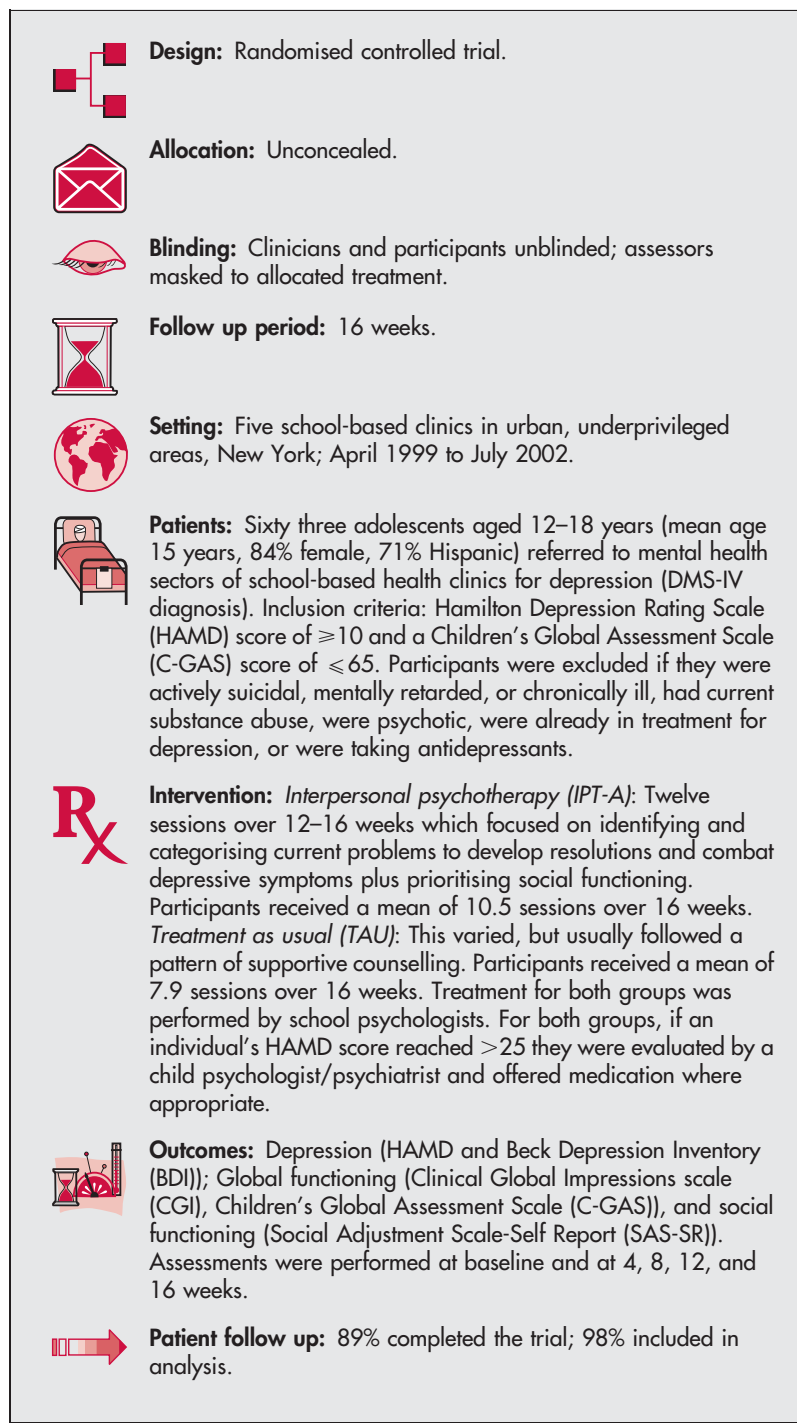

\section{MAIN RESULTS}

At 12 weeks, IPT-A reduced depression compared with TAU (mean HAM-D score: $8.7 v 12.8, \mathrm{p}=0.04$; mean BDI score: $8.4 \vee 12.3$, $\mathrm{p}=0.14$ ). IPT-A significantly improved global and social functioning compared with TAU (global functioning: mean CGI scores (severity) For correspondence: Laura Mufson PhD, New York State Psychiatric Institute, 1051 Riverside Drive, Unit 24, New York, NY 10032, USA; MufsonL@childpsych.columbia.edu

Sources of funding: Substance Abuse and Mental Health Administration, Rockville, and Psychotherapy Core of the National Institute of Mental Health Child Psychiatry Intervention Research Center, Rockville.
$2.4 v$ 3.0, $\mathrm{p}=0.03$; mean CGI scores (improvement) $2.3 v 3.1$, $\mathrm{p}=0.03$; mean C-GAS scores $66.7 v 59.5, \mathrm{p}=0.04$; social functioning: mean SAS-SR score: $2.23 v 2.59, \mathrm{p}=0.01$ ). At 16 weeks, depressive symptoms were still significantly reduced with IPT-A, but improvements in global functioning were slightly attenuated (mean HAM-D score: $6.9 v 10.6, \mathrm{p}=0.04$, effect size 0.51 (95\% CI 0.003 to 1.02 ); C-GAS trend to improvement, $\mathrm{p}=0.06$ ). Subgroup analysis found that the effects of IPT-A were much greater in older adolescents.

\section{CONCLUSIONS}

Interpersonal psychotherapy is effective in the school-based treatment of depression, especially in older adolescents.

\section{Commentary}

D epression is a chronic illness with a high burden of disability. One third of first episodes occur before the age of $21 .^{1}$ It makes good sense to identify adolescent depression early and provide effective treatment.

Unfortunately, the evidence for effective treatment of depression in adolescence is limited. There is good evidence for three interventions: medication, cognitive behavioural therapy (CBT) and interpersonal psychotherapy (IPT-A). All three have some problems. Many antidepressants have either not been adequately researched in adolescence, or appear to be ineffective. Only fluoxetine has data from several trials. ${ }^{2}$ There is also concern that SSRIs may increase suicidal behaviour in young people. ${ }^{3}$ While this needs further evaluation, alternatives to medication are needed. CBT has good evidence for effectiveness ${ }^{4}$ but does not suit all patients. IPT-A has several potential advantages. There have been other well conducted trials using a treatment manual. ${ }^{5}$

Using rigorous methodology, the current study found IPT-A to be effective in a school setting, reducing depressive symptoms and improving functioning. This study is useful for clinical practice for several reasons. The treatment was conducted in a school setting by the school clinicians, providing "real world" subjects and clinicians. IPT-A was simple to learn, by reading a manual, participating in two days of training, and attending weekly supervision. Participants were not withdrawn from the study if they were on antidepressants. The severity of depression ranged from mild to severe, with the mean at the lower end in the moderate to severe range. Only suicidal young people were excluded.

Although trials in other community settings would be useful, this is an encouraging finding and supports the addition of IPT-A to the treatment repertoire of those working with depressed adolescents. Jean Starling, MBChB, FRANZCP, MPH Head of Department of Psychological Medicine, The Children's Hospital, Westmead, NSW, Australia

1 Andrews $G$, Szabo $M$, Burns J. Preventing major depression in young people. Br J Psychiatry 2002;181:460-2.

2 Emslie GJ, Heiligenstein JH, Hoog SL, et al. Fluoxetine treatment for prevention of relapse of depression in children and adolescents: a doubleblind, placebo controlled study. J Am Acad Child Adolesc Psychiatry 2004;43:1397-405.

3 American College of Neuropsychopharmacology. Preliminary report of the Task force on SSRIs and suicidal behavior in youth. American College of Neuropsychopharmacology, January 2004. Available at hitp:// www.acnp.org/exec_summary.pdf (accessed November 2004).

4 Reinecke MA, Ryan NE, DuBois DL. Cognitive-behavioural therapy of depression and depressive symptoms during adolescence: a review and meta-analysis. J Am Acad Child Adolesc Psychiatry 1998;37:26-34.

5 Mufson L, Moreau D, Weissman MM, et al. Interpersonal psychotherapy for depressed adolescents. New York, NY: Guildford Publications, 1993. 